\title{
El fuego en cárceles de nieve: del secreto amoroso en la comedia cal- deroniana ${ }^{\top}$
}

\section{The fire in snow prisons: concerning the secret of love in Calderonian comedia}

\author{
Alicia Vara López \\ GIC-Universidad de Viena \\ AUSTRIA \\ aixavara@gmail.com \\ [Hipogrifo, (issn: 2328-1308), 2.1, 2014, pp. 73-85] \\ Recibido: 09-10-2013 / Aceptado: 18-11-2013 \\ DOI: http://dx.doi.org/10.13035/H.2014.02.01.05
}

Resumen. El principal objetivo del presente trabajo es encontrar un patrón que explique la extraordinaria rentabilidad de las alusiones al decir sin decir asociadas a la ocultación y revelación del secreto de amor, uno de los temas más recurrentes en el universo calderoniano. Para ello, se analizarán pasajes extraídos de nueve comedias de diversos géneros y etapas, que, por tanto, pueden considerarse una muestra representativa del modus scribendi calderoniano.

Palabras clave. Calderón de la Barca, secreto de amor, universo barroco, comedias.

Abstract. The main objective of this article is to find a pattern that explains the extraordinary profitability of the allusions to the decir sin decir, related to the hiding and revelation of the secret of love, one of the most recurrent themes in the Calderonian universe. For this, we will analyze fragments extracted from nine comedias of various genres and stages, which therefore can be considered a representative sample of the Calderonian modus scribendi.

Keywords. Calderón de la Barca, Secret of Love, Baroque Universe, Comedias.

1. Este trabajo forma parte del proyecto «Secrets and Secrecy in Calderón's Comedies and in Spanish Golden Age Culture. Including a Critical Edition of El secreto a voces» (P 24903-G23), financiado por Austrian Science Fund FWF y desarrollado en la Universidad de Viena. Agradezco a su investigador principal, el profesor Wolfram Aichinger, la idea de este artículo y la confianza depositada en su autora. Además, el presente estudio se ha visto beneficiado por mi participación en el Proyecto de Investigación de la DGICYT, dirigido por Luis Iglesias Feijoo (FFI2012-38956), y en el Proyecto Consolider-Ingenio CSD2009-00033 sobre «Patrimonio teatral clásico español» TECE-TEl (conocido como TC-12). 
Los motivos del secreto y el silencio han dado lugar a estudios desde diversos enfoques, aplicados al Siglo de Oro en general o a la producción calderoniana en particular ${ }^{2}$. En este último grupo, fueron principal objeto de interés obras en cuyo título figura de forma explícita el tema central de la ocultación de un suceso o circunstancia de cara a la esfera pública (El secreto a voces, Nadie fíe su secreto, A secreto agravio, secreta venganza, Basta callar...). Sin embargo, ha pasado más desapercibido el hecho de que la reiterada tensión entre el hablar y el callar, plasmada en distintos planos del discurso, entronca con el gusto generalizado del dramaturgo por la dualidad y los contrastes, de forma que llega a erigirse como un sello de identidad que conecta la obra de Calderón con el universo barroco y sus paradojas ${ }^{3}$.

Conviene dejar clara la distinción entre secreto y silencio, ya que, aunque se trata de términos semánticamente muy próximos, entre ellos existe una relación de causalidad, en tanto que el silencio, al igual que la mentira o el disimulo, surge como una de las fórmulas de protección del secreto. No obstante, en el teatro calderoniano no cabrían los secretos sin la posibilidad, siempre latente, de ser compartidos o descubiertos. En este sentido, el silencio que los protege -lejos de equipararse a un muro monolítico e impenetrable- muestra grietas estratégicamente dispuestas para que ciertas informaciones afloren en medidas dosis. De este modo, se establecen dos bandos de personajes en oposición que terminan por disolverse cuando se produce la anagnórisis: los privilegiados portadores del secreto frente a los que lo desconocen o lo intuyen. En este ambiente de confrontación, que propicia innumerables juegos de apariencias y equívocos, tanto los calculados silencios como las alusiones al callar contribuyen a la creación de una expectativa, una intriga creciente, imprescindible para la construcción del enredo.

El presente trabajo se centrará en el «secreto de amor», sin duda uno de los más recurrentes y fructíferos del universo calderoniano ${ }^{4}$. Aurora Egido señala que el motivo constante de la «guarda del secreto» de amor «a través de ocultamientos, silencios y señales minuciosamente codificados» desciende de la lírica trovadoresca y de la tradición del amor cortés ${ }^{5}$. Más adelante, continuó vigente en la poesía renacentista y fue adoptado por la comedia nueva como una de las principales fuentes de tensión dramática. Calderón selecciona, reelabora y combina una serie de tópicos del secreto de amor con tal frecuencia que se convierten en rasgos

2. Véanse Parker, 1973; Neumeister, 1982; Egido, 1986, 1990, 1995; Déodat-Kessedjian, 1999; Rodríguez de la Flor, 2005; Snyder, 2009; Castro, 2013; Casariego, en prensa; Aichinger, en prensa; y Kroll, en prensa. 3. La dualidad en la dramaturgia calderoniana ha sido ampliamente estudiada de manera general (Gitlitz, 1984) o en comedias concretas. Sirvan como muestra los trabajos acerca de La vida es sueño (Casalduero, 1967), Hado y divisa de Leonido y Marfisa (Tobar, 1984), Los cabellos de Absalón (Lauer, 1988), Amor, honor y poder (Vara López, 2011), Casa con dos puertas (Iglesias Feijoo y Hernando Morata, 2013) o La estatua de Prometeo (Iglesias Feijoo y Vara López, 2013).

4. Wolfram Aichinger afirma que «Todos los secretos y subsecretos derivan de tres secretos principales: el secreto amoroso (o erótico), el secreto de un crimen y el misterio del parentesco no revelado. Los dos últimos casi siempre están relacionados con el primero ya que son amores y pasiones que desembocan en crímenes» (en prensa).

5. Egido, 1986, p. 96. 
paradigmáticos de su teatro. Ya en Lances de amor y fortuna, Rugero se vale de la figura de la correlación para formular una completa definición del amor perfecto, como sabio, solo, solícito y, lo que importa más aquí, secreto 6 . Décadas después, el dramaturgo reutiliza la misma estructura en Ni Amor se libra de amor?

La ocultación del sentimiento amoroso se integra en un aparato poético y simbólico que recrea la vinculación entre el amor y el honor, dos de las piedras angulares del tejido dramático calderoniano. El dilema entre la necesidad de exteriorizar las pasiones y el deber de preservar el decoro concuerda con el gusto general del dramaturgo por los contrastes y la paradoja, manifestado en lo que Déodat-Kessedjian denominó «estilística del silencio» ${ }^{8}$. De acuerdo con estos presupuestos, el principal objetivo de las siguientes líneas es buscar un valor o función que explique la extraordinaria rentabilidad de las alusiones al decir sin decir aplicadas al secreto de amor. Se seleccionarán fragmentos extraídos de nueve comedias, en su mayoría poco estudiadas al respecto del tema del secreto 9 . Se han escogido dichas obras porque fueron compuestas en una amplia franja cronológica, que se extiende desde 1625 hasta 1661, pertenecen a géneros tan diversos como la comedia bizantina, la fiesta mitológica, la comedia de capa y espada o la tragedia y, por tanto, pueden considerarse una muestra representativa del modus scribendi calderoniano.

Desde el principio de su producción, Calderón vislumbra el silencio como uno de los lenguajes de los amantes. En Lances de amor y fortuna se llega a la conclusión de que «el silencio es retórica de amantes», como broche final a una compleja reflexión en tono argumentativo acerca del amor silenciado y del silencio elocuente ${ }^{10}$ :

ESTELA Harto el silencio con callar responde, harto dice la lengua a veces muda; pues si el conceto, que en el alma esconde, no es posible que igual al labio acuda, calla quien ama a estremos semejantes, que el silencio es retórica de amantes. (Comedias, I, p. 714)

La tradicional mudez del enamorado también se presenta de forma reiterada en La dama duende, cuando Ángela destaca la incapacidad física de los amantes para verbalizar el amor: «Quiso hablarme y no pudo, / que siempre ha sido el sen-

6. Comedias, I, pp. 739-740.

7. Comedias, III, pp. 879, 881-882.

8. Déodat-Kessedjian, 1999, p. 40

9. Lances de amor y fortuna (h. 1625), Argenis y Poliarco (h. 1627-1629), El médico de su honra (h. 1629), La dama duende (1629), El mayor encanto, amor (1635), El encanto sin encanto (h. 1650), También hay duelo en las damas (h. 1652-1653), Eco y Narciso (1661) y Ni Amor se libra de amor (1661).

10. En Eco y Narciso se localiza la misma alusión a la simultaneidad del hablar y callar sobre el amor, lo cual demuestra la permanencia de dicha paradoja a lo largo de su trayectoria creadora. La insistente petición de silencio, destacada mediante la derivatio (calle, calle, callar), se contrapone a la necesidad de expresar el amor (me declare, hable, hablar): «ECO: Vos que me declare y vos / que calle solicitáis; / y yo en la duda en que estáis / he de igualar a los dos. / Deme, pues, el ciego dios / industria para que aquí / hable y calle. Solo así / el callar y hablar se infiere», Comedias, IV, p. 148. 
timiento mudo. / [...] Yo responderle intento / -ya he dicho cómo es mudo el sentimiento- / y, aunque quise, no pude ${ }^{11}$. Valbuena Briones ${ }^{12}$ destaca la tendencia al balbuceo como una reacción propia del enamorado del universo barroco. Este estado de incapacidad verbal se muestra de forma clara en los intentos frustrados de Enrique por expresar sus sentimientos en El encanto sin encanto. Su discurso entrecortado suscita un instante de tensión dramática extrema, reflejado en una alteración del ritmo y la fluidez del verso: «Y yo... si... cuando... ¿Qué digo? / Perdonad, que hablar no puedo» ${ }^{13}$. En Ni Amor se libra de amor se localiza esta misma idea de la paralización, manifestada en el recurso de la dubitatio, que se expresa en el quebrantamiento sinecdótico de Siquis en distintas partes del cuerpo, incapaces de reaccionar, respirar ni expresarse, si bien en este caso el motivo de dicha reacción es el temor y no el amor. La enumeratio de siete miembros, con clara función acumulativa, pone de manifiesto el colapso del individuo ${ }^{14}$.

$\begin{array}{ll}\text { bIQUIS } & \text { balbuciente el labio duda, } \\ & \text { torpe la voz titubea, } \\ & \text { turbado el aliento pasma, } \\ & \text { aterido el pecho tiembla, } \\ & \text { mudo fallece el suspiro, } \\ & \text { la vista delira ciega, } \\ & \text { y el corazón a pedazos } \\ \text { parece que se me quiebra, } & \text { según el tropel de tantas } \\ \text { ilusiones y quimeras, } & \text { fantasías y pavores, } \\ & \text { ansias, desdichas y penas, } \\ \text { en crítico parasismo } & \text { ni ve, ni escucha, ni alienta. } \\ \text { (Comedias, III, pp. 854-855) }\end{array}$

En Lances de amor y fortuna la incapacidad de expresión no obedece a causas físicas inherentes al enamorado, sino a su promesa de silencio. En este caso, el recurso de la preterición aparece en una formulación explícita del compromiso de guardar en secreto el amor. El juramento se refuerza con la transfiguración metafórica de Lotario en una estatua ofrecida a la fe de la amada divinizada, situada como objeto de culto ${ }^{15}$ :

LOTARIO sabed que os adoro yo y vos no lo agradezcáis, aunque, si vos misma halláis

11. Comedias, I, pp. 853-854.

12. Valbuena Briones, 1956, p. 1915.

13. Comedias, IV, p. 428.

14. Este tipo de enumeraciones, en alusión a las mismas partes del cuerpo, es muy habitual en el dramaturgo. Comp. Basta callar, vv. 1225-1230; La cisma de Inglaterra, vv. 105-110; y El mayor monstruo del mundo, Comedias, II, p. 564.

15. Para una asociación de la metáfora de la estatua con el silencio véase Déodat-Kessedjian, 1999, p. 49. 


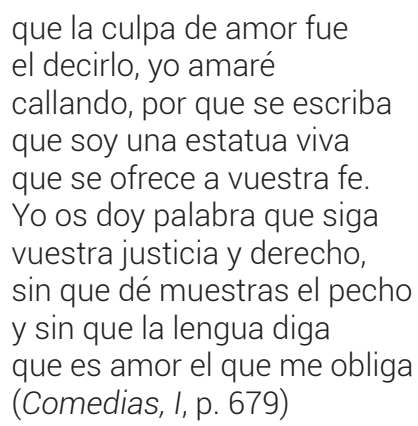

En Argenis y Poliarco son misteriosos elementos, también externos a la enamorada, los que imponen el doloroso silencio de Selenisa. La dama no responsabiliza de su actitud callada a alguien en concreto, sino que se refiere a una presión social indeterminada, que la condena a una hiperbólica muerte: «Si no me dejan hablar, / yo moriré de temor, / que no hay tristeza en amor / como sufrir y callar» (vv. 32343237). Esta dama halla en las canciones la única vía posible para manifestar sus penas $^{16}$. El intenso sentimiento que oculta Selenisa se destaca en su canto por medio de la alusión indirecta e hipotética al momento de su declaración ${ }^{17}$ :

SELENISA ¡Qué tarde remedio espera

quien ama y no se declara!,

que yo pienso que, si hablara,

hasta las piedras moviera.

El callar me ha de matar

sufriendo tanto rigor...

(vv. 3250-3255)

En el contexto trágico de El médico de su honra reaparece la misma referencia a la confesión del amor en un plano hipotético o desiderativo. Doña Mencía interpela a los cielos y les manifiesta el deseo de desahogar su pena, con la reiterativa fórmula «iOh, quién pudiera!». Mediante este recurso distanciador, consigue sugerir un amor silenciado sobre el que no puede «hacer sentimientos» ni «dar voces». Los espectadores se mantendrían concentrados en descifrar el contenido profundo de sus ambiguas palabras. La intensidad dramática llega a un punto álgido con la mención de dos imágenes muy características del silencio de amor, ya desde

16. De acuerdo con la concepción platónica de la música como agente activo en el ánimo, Querol, 1983, p. 1158, afirma que «muchos de los personajes en el teatro calderoniano buscan» en ella «el alivio de sus tristezas». El motivo de la ruptura del silencio amoroso a través del canto y las lágrimas se localiza ya en la poesía trovadoresca, como afirma Aurora Egido, 1990, pp. 59-60. En el teatro calderoniano pueden verse pasajes similares en El mayor encanto, amor, Comedias, II, p. 83, o El monstruo de los jardines, Comedias, IV, p. 245

17. Déodat-Kessedjian, 1999, pp. 43-44, afirma que el recurso según el cual «un personaje confiesa su amor negándolo [...] acrecienta la importancia de lo que se quiere disimular, imponiendo al interlocutor una escucha descifradora, interpretadora. [...] el dramaturgo concede a su personaje una revelación parcial sin la obligación de asumir la responsabilidad de lo dicho». 
la poesía cancioneril: la metáfora ígnea y la carcelaria ${ }^{18}$. La oposición cromática y térmica entre las cárceles de nieve y el fuego interior refuerza la lucha de doña Mencía por romper el silencio que la mortifica. Calderón eleva mediante recursos estilísticos y simbólicos la fuerza expresiva del parlamento y aprovecha este instante de máxima tensión para abrir una brecha en el silencio ${ }^{19}$. La dama permite por un instante que el fuego que la devora, convertido en las características cenizas y ruina, hable en su nombre y reconozca su amor secreto. Con todo, inmediatamente después se produce una correctio y la enamorada reprime su confesión aludiendo a su condición noble ${ }^{20}$. Tras el inevitable desbordamiento, doña Mencía vuelve a encarcelar sus sentimientos, pidiendo al aire que le devuelva los «repetidos acentos» de su amor:

DOÑA MENCÍA $\quad[. .$.$] ¡Oh, quién pudiera, ah, cielos,$
con licencia de su honor
hacer aquí sentimientos!
¡Oh, quién pudiera dar voces
y romper con el silencio
cárceles de nieve donde
está aprisionado el fuego,
que ya, resuelto en cenizas,
es ruina que está diciendo:
«Aquí fue amor»! Mas ¿qué digo?
¿Qué es esto, cielos, qué es esto?
Yo soy quien soy. Vuelva el aire
los repetidos acentos
que llevó, porque, aun perdidos,
no es bien que publiquen ellos
lo que yo debo callar,
porque ya con más acuerdo
ni para sentir soy mía,
y solamente me huelgo
de tener hoy qué sentir
por tener en mis deseos
qué vencer, pues no hay virtud
sin esperiencia. [...]
¡Viva callando, pues callando muero!
(Comedias, II, pp. 393-394)

18. Para un estudio de la cárcel como tópico del secreto en el teatro calderoniano véase Déodat-Kessedjian, 1999, p. 47. Casas Rigall, 1995, estudia la metáfora ígnea (pp. 71,72, 73-74, 102, 210) y la carcelaria (pp. 71, 72, 89, 238) en la poesía de cancionero.

19. «El secreto amoroso está, pues, primero ubicado en el pecho de los enamorados, en situación de prisionero y condenado a pena de larga duración. La vigilancia es de la más severa. [...] Pero es prisionero indómito con unas ansias tremendas de salir en libertad. En algún momento se le concede la libertad al secreto prisionero, libertad condicional por cierto porque pocas veces se revela en la plaza pública, sino a unos confidentes», Aichinger, en prensa.

20. Valbuena Briones, 1956, vol. II, p. 1915, relaciona el Barroco con «titubeo, inquietud, contracción» y con la tendencia al desdecirse. 
En El encanto sin encanto se localiza un pasaje paralelo en el que una vez más la figura dialéctica de la correctio sirve para que la enamorada proceda a la contentio de sus sentimientos, apenas liberados. Serafina se interrumpe de forma precipitada cuando se disponía a hablar sobre el amor y, en dos versos paralelísticos, ordena a la voz que se encierre en el pecho y al suspiro que vuelva al alma. El silencio se personifica como único testigo válido para su tormento:

$\begin{array}{ll}\text { SERAFINA } & \text { [...] Ciega } \\ & \text { debo de estar, pues que sigo } \\ & \text { ajenos pasos que doy } \\ & \text { a la elección de otro arbitrio. } \\ & \text { Pero, jay, infeliz!, ¿qué puedo } \\ & \text { hacer cuando...? Mas ¿qué digo? } \\ & \text { ¡Vuélvase al pecho la voz! } \\ & \text { ¡Vuélvase al alma el suspiro! } \\ & \text { Pues a despecho del labio, } \\ & \text { solo el silencio testigo } \\ & \text { ha de ser de mi tormento. } \\ & \text { (Comedias, IV, p. 415) }\end{array}$

En El mayor encanto, amor se recoge otra destacable metáfora ígnea asentada en una alusión a la mítica guerra de Troya. Circe se identifica a sí misma como Troya, en la que Ulises introduce un «fuego de amor» tan voraz que acabará por convertirla en cenizas. Como suele suceder, el deseo de contención de los sentimientos no llega a impedir la existencia de ciertas vías de escape. En este caso, las propias palabras de la maga actúan como eco de su amor, aludido mediante las prototípicas metáforas del aliento y los suspiros, transmutados en volcanes que emanan de su interior y exhalan fuego:

$\begin{array}{ll}\text { CIRCE } & \text { Este Ulises, este griego } \\ & \text { que esa marítima bestia } \\ & \text { sorbió sin duda en el mar } \\ \text { para escupirle en la tierra; } & {[. . .]} \\ & \text { como si fuera mi vida } \\ & \text { Troya, ha introducido en ella } \\ & \text { tanto fuego que en cenizas } \\ & \text { no dudo que se resuelva, } \\ & \text { y con razón, porque ya, } \\ & \text { en callado fuego envuelta, } \\ & \text { cada aliento es un Volcán, } \\ \text { cada suspiro es un Etna. } \\ \text { (Comedias, II, p. 40) }\end{array}$

En El encanto sin encanto también se ilustra la misma tendencia a expresar el amor mediante recursos artificiosos y velados. En esta ocasión, Libia recomienda a los enamorados que compartan sus sentimientos de una manera indirecta y alambicada, que resulta ser la clave de la retórica del silencio («sin que tú le hables, / le 
hables tú y, sin que él contigo / hable, contigo hable»). La tópica sagacidad de la dama tramoyera se manifiesta aquí en sus consejos orientados a salvaguardar el decoro. En su discurso se acumulan antítesis y paradojas:

LIBIA $[.$.$] sin que tú le hables,$
le hables tú y, sin que él contigo
hable, contigo hable, y esto
sin deshacer los motivos
que de Margarita y Laura
creyó, llevando sabido
y ignorado quién le da
la vida, haciendo que al mismo
tiempo su imaginación
descanse en el punto fijo
de la verdad sin verdad,
llegando el ingenio mío
a callarlo sin callarlo
y a decirlo sin decirlo.
(Comedias, IV, pp. 414-415)

Ante la necesidad de ocultar las «calladas tristezas», en Ni Amor se libra de amor son los ojos, identificados con «cristalinas vidrieras», los que revelan lo mismo que pretenden ocultar ${ }^{21}$. La plasmación poética de la elocuencia de los ojos es un tópico muy extendido en la obra calderoniana que encaja con la visión de personajes desbordados por un torrente de sentimientos silenciados 22 .

$\begin{array}{ll}\text { SIQuIs } & \text { Por todo el camino vas } \\ & \text { entre calladas tristezas, } \\ & \text { tanto sintiendo y llorando, } \\ & \text { como si por dicha fuera, } \\ \text { o por desdicha, posible } & \text { dar tan mañosa cautela } \\ & \text { que finja el dolor; que como } \\ & \text { son cristalinas vidrieras } \\ & \text { del alma los ojos, cuanto } \\ & \text { parece que ocultan, muestran. } \\ & \text { (Comedias, III, p. 854) }\end{array}$

En este mismo sentido, en Argenis y Poliarco los verdaderos pensamientos de Argenis se muestran por medio del artificioso recurso del aparte, de forma que se abre un canal de comunicación alternativo y directo al público que alude a la dificul-

21. En este caso no se trata de un secreto amoroso, sino que Atamas oculta el propósito de sacrificar a su hija, por orden de Júpiter.

22. Comp. El galán fantasma: «Eso díselo a mis ojos, / porque, si son mudas lenguas / del alma, no caIlarán / a Carlos nada que sepan», Comedias, II, p. 241. 
tad para encubrir un sentimiento tan poderoso, cuando todo su cuerpo la delata ${ }^{23}$. Destaca aquí la personificación de tres elementos identificados metonímicamente con el yo: la lengua, que disimula y finge; los ojos, que lloran, y el alma, «que no miente». Las «lenguas de cristal», asociadas a los expresivos ojos, se identifican con las «lenguas de fuego» bíblicas, en cuanto a su significado de 'anuncio'24. No obstante, en un giro muy característico del dramaturgo, el elemento del fuego se transmuta en agua (cristal) para referirse a las lágrimas:

ARGENIS Y es justa ley que muera. (¿Qué aprovecha disimular, fingir la lengua enojos,

si lenguas de cristal hablan los ojos y el alma, que no miente,

dice una cosa y otra cosa siente?)

(vv. 861-865)

Otro de los procedimientos calderonianos para la articulación de la tensión entre el decir y el callar es la utilización del recurso de la esticomitia. En el ejemplo que se muestra a continuación, de También hay duelo en las damas, se manifiesta una estructuración bimembre de los versos, que facilita la repartición de las intervenciones alternas de los locutores: don Félix solicita recurrentemente la información, mientras que su amada Violante se la niega. De este modo, se instaura un ritmo pendular que ayuda a reforzar la agitación y la confrontación dialéctica ${ }^{25}$.

$\begin{array}{lc}\text { DON FÉLIX } & \text { Mucho dices. } \\ \text { VIOLANTE } & \text { Pues más callo. } \\ \text { DON FÉLIX } & \text { Pueho callas. } \\ \text { VIOLANTE } & \text { ¿Qué te obliga? } \\ \text { DON FÉLIX } & \quad \text { Una atención. } \\ \text { VIOLANTE } & \text { ¿Qué te embaraza? }\end{array}$

23. Aichinger, en prensa, afirma que «siempre el secreto vive expuesto a grandes riesgos. Peligra por su extraña manía de emitir señales incluso desde los lugares más recónditos -como lo sería el pecho de una dama; expuesto al escrutinio de un padre receloso o un amante celoso [...]. Los reflejos y expresiones involuntarias del cuerpo traicionan lo que debería permanecer guardado detrás de muros impenetrables».

24. Hechos de los Apóstoles, 2, 2-4. Comp. Amor, honor y poder: «Afligido pensamiento, / que en tan confusos enojos, / haciendo lenguas los ojos, / decís vuestro sentimiento», Comedias, II, p. 976.

25. En El encanto sin encanto, Comedias, IV, pp. 421-428, se muestra la misma oposición entre la solicitud de información por parte del personaje masculino y la negación de la dama. El imperativo «háblame claro» destaca otra vez la rentabilidad de sembrar el desconcierto en ciertos personajes no conocedores del secreto. El amor se vislumbra velado por confusiones, artificios retóricos y referencias al silencio. A todo ese entramado simbólico se suman, a nivel escenográfico, el disfraz, las máscaras y la música, elementos que inciden en el mismo propósito de juego y de revelación encubierta. 


\begin{tabular}{lc} 
VIOLANTE & \multicolumn{2}{c}{ Un respeto. } \\
DON FÉLIX & ¿Qué sabes? \\
VIOLANTE & \multicolumn{1}{c}{ No me atrevo. } \\
DON FÉLIX & Declárate. \\
VIOLANTE & No me animo. \\
DON FÉLIX & Hácate. \\
VIOLANTE & ¿Por qué? \\
DON FÉLIX & El secreto juré. \\
VIOLANTE &
\end{tabular}

(Comedias, III, p. 1323)

Los pasajes seleccionados ilustran distintas manifestaciones estilísticas y simbólicas del secreto de amor en diversos géneros y etapas. Más que profundizar en las peculiaridades de cada una de estas comedias o realizar una presentación exhaustiva de todos los recursos estilísticos asociados al silencio, interesa en esta ocasión identificar un patrón constructivo global que permita explicar la rentabilidad dramática de las distintas fórmulas del decir sin decir en el contexto amoroso. Se ha puesto de manifiesto que la recurrente alusión al silencio encubre y a la vez facilita la presentación de informaciones tan comprometedoras para el enamorado como esenciales para mantener viva la tensión dramática. El esfuerzo por la contención no impide que las emociones se manifiesten por medio de vías alternativas, como la elocuencia de los ojos o las metáforas ígneas y carcelarias ${ }^{26}$. Recursos omnipresentes como la enumeratio, la preterición o la hipérbole acentúan el desahogo de las pasiones, de manera que el secreto amoroso -callado, negado o disimulado - traspasa las prisiones y barreras que lo encierran y llena el escenario. Se puede concluir, pues, que el principio ordenador que otorga sentido a todos los textos analizados es la continua alternancia entre la contención y la expresión del sentimiento, que contempla distintos grados que van desde el silencio o la negación hasta la ruptura del secreto, pasando por estadios intermedios como la insinuación o la revelación hipotética. Detrás de todo el entramado simbólico que rodea al silencio elocuente de amor se alza una de las máximas esenciales del arte barroco: la búsqueda de una reacción de admiratio que los personajes contagiarían a los espectadores con la finalidad de asegurar el funcionamiento de la obra en las tablas ${ }^{27}$. Calderón crea un desfile de máscaras, un artificioso juego de luces y

26. Rodríguez de la Flor, 2005, p. 28, afirma que en el universo barroco prima «La censura violenta de la interioridad, a favor de una construcción del sujeto que se vea "tolerada" por el mundo». Se produce, por tanto, una «tensión especial, una "angustia epocal", fundada por la oposición dialéctica de interioridad y exterioridad, así como sus derivados y consecuencias: la oposición público/privado, público/secreto». 27. Para un estudio del concepto de la admiración en la poesía barroca véase Egido, 1990, pp. 19-28. 
sombras, asentado en la estética del claroscuro, que agudiza los sentidos y excita la imaginación de aquellos que no son portadores del secreto, mientras que los que deben guardarlo se enfrentan a casualidades y situaciones de lo más peregrino que ponen en riesgo su silencio a cada paso, causando inquietud, sorpresa y perplejidad. En definitiva, los personajes del universo amoroso calderoniano, sujetos a los vaivenes de la fortuna y a la tiranía del ser quien soy, vacilan entre la contentio y el desbordamiento de sus pasiones en un movimiento pendular constante que los convierte en productos paradigmáticos del universo barroco.

\section{BIBLIOGRAFÍA}

Aichinger, Wolfram, «El secreto en la comedia de Calderón y en la vida cortesana», en Pictavia aurea. Actas del IX Congreso de la Asociación Internacional «Siglo de Oro», eds. Alain Bègue y Emma Herrán, Toulouse, Presses Universitaires du Mirail (Anejos de Criticón, 19), en prensa.

Calderón de la Barca, Pedro, Obras completas. Comedias, ed. Ángel Valbuena Briones, Madrid, Aguilar, 1956.

Calderón de la Barca, Pedro, La cisma de Inglaterra, ed. Francisco Ruiz Ramón, Madrid, Castalia, 1981.

Calderón de la Barca, Pedro, Basta callar, ed. Daniel Altamiranda, Kassel, Reichenberger, 1995.

Calderón de la Barca, Pedro, Comedias, I. Primera parte de comedias, ed. Luis Iglesias Feijoo, Madrid, Biblioteca Castro, 2006.

Calderón de la Barca, Pedro, Comedias, II. Segunda parte de comedias, ed. Santiago Fernández Mosquera, Madrid, Biblioteca Castro, 2007.

Calderón de la Barca, Pedro, Comedias, III. Tercera parte de comedias, ed. Don William Cruickshank, Madrid, Biblioteca Castro, 2007.

Calderón de la Barca, Pedro, Comedias, IV. Cuarta parte de comedias, ed. Sebastian Neumeister, Madrid, Biblioteca Castro, 2010.

Calderón de la Barca, Pedro, «Argenis y Poliarco» de Calderón de la Barca: edición crítica y estudio dramático, ed. Alicia Vara López, Madrid/Frankfurt am Main, Iberoamericana/Vervuert, en prensa.

Casalduero, Joaquín, «Sentido y forma de La vida es sueño», en Estudios sobre teatro español, Madrid, Gredos, 1967, pp. 164-184.

Casariego Castiñeira, Paula, «Nadie fíe su secreto», comunicación presentada en el Simposio Internacional «Palabra y poder: silencios y secretos en el teatro del Siglo de Oro», celebrado en Viena del 14 al 15 de mayo de 2013, en prensa.

Casas Rigall, Juan, Agudeza y retórica en la poesía amorosa de cancionero, Santiago de Compostela, Universidade de Santiago de Compostela, 1995. 
Castro Rivas, Jéssica, «Secreto y silencio en La banda y la flor de Calderón de la Barca», en «Festina lente». Actas del II Congreso Internacional de Jóvenes Investigadores Siglo de Oro (JISO 2012), ed. Carlos Mata Induráin, Adrián J. Sáez y Ana Zúñiga Lacruz, Pamplona, Servicio de Publicaciones de la Universidad de Navarra, 2013, pp. 65-77.

Déodat-Kessedjian, Marie-Françoise, El silencio en el teatro de Calderón, Madrid/ Frankfurt am Main, Iberoamericana/Vervuert, 1999.

Egido, Aurora, «La poética del silencio en el Siglo de Oro. Su pervivencia», Bulletin Hispanique, 88.1-2, 1986, pp. 93-120.

Egido, Aurora, Fronteras de la poesía en el Barroco, Crítica, Barcelona, 1990.

Egido, Aurora, "La vida es sueño y los idiomas del silencio», en El gran teatro de Calderón: personajes, temas, escenografía, Kassel, Reichenberger, 1995, pp. 217-234.

Gitlitz, David M., «Architecture and the comedia», Bulletin of the Comediantes, 36, 1984, pp. 23-31.

Iglesias Feijoo, Luis, e Isabel Hernando Morata, «Dualidad y paralelismos en Casa con dos puertas mala es de guardar, de Calderón», Anuario calderoniano, 6, 2013, pp. 111-131.

Iglesias Feijoo, Luis, y Alicia Vara López, «De luces, sombras y asombros: una lectura de La estatua de Prometeo», Anuario calderoniano, vol. extra 1, 2013, pp. 213-233.

Kroll, Simon, «Tiempo y secreto en algunas obras calderonianas», comunicación presentada en el XVI Congreso de la AITENSO: Tiempo e historia en el teatro español del Siglo de Oro, celebrado en Aix-en-Provence del 25 al 27 de septiembre de 2013, en prensa.

Lauer, A. Robert, «The Dramatic Symmetry of Calderon’s Los cabellos de Absalón: a Semiotic Reading», Romanistiches Jahrbuch, 39, 1988, pp. 323-341.

Neumeister, Sebastian, «Saber y callar. Apuntes para una socio-patología del Siglo de Oro», en Actas del Coloquio hispano-alemán Ramón Menéndez Pidal: Madrid, 31 de marzo a 2 de abril de 1978, ed. Wido Hempel y Dietrich Briesemeister, Tübingen, Niemeyer, 1982, pp. 218-228.

Parker, Alexander, «Los amores y noviazgos clandestinos en el mundo dramáticosocial de Calderón», en Hacia Calderón. Segundo Coloquio Anglogermano, Hamburgo, 1970, ed. H. Flasche, Berlin/New York, Walter de Gruyter, 1973, pp. 79-87.

Querol, Miguel, «La dimensión musical de Calderón», en Calderón. Actas del «Congreso internacional sobre Calderón y el teatro español del Siglo de Oro», Madrid, 8-13 de junio de 1981, ed. Luciano García Lorenzo, Madrid, CSIC, 1983, vol. II, pp. 1155-1160. 
Rodríguez de la Flor, Fernando, Pasiones frías: secreto y disimulación en el Barroco hispano, Madrid, Marcial Pons, 2005.

Snyder, Jon R., Dissimulation and the Culture of Secrecy in Early Modern Europe, Berkeley/London, University of California Press, 2009.

Valbuena Briones, Ángel, 1956 (véase Calderón de la Barca, Calderón, Obras Completas. Comedias).

Vara López, Alicia, «Del concepto a la forma: la dualidad en Amor, honor y poder», en Compostela áurea. Actas del «Octavo Congreso de la Asociación Internacional Siglo de Oro (AISO)», Universidade de Santiago de Compostela, 7-11 de julio de 2008, ed. Antonio Azaustre Galiana y Santiago Fernández Mosquera, Santiago de Compostela, Universidade de Santiago de Compostela, 2011, vol. III, pp. 507-512. 
